Original Article

\title{
OCCURRENCE OF IRON DEFICIENCY ANEM IA BETWEEN OVER WEIGHT AND NORMAL WEIGHT ADOLESCENTS IN SELECTED SCHOOLS IN UDUPI DISTRICT
}

\author{
Sujatha . $^{1} \&$ Reshma ${ }^{2}$ \\ Professor \& HOD ${ }^{1}$, Lecturer ${ }^{2}$, Department of Pediatric Nursing, Nitte Usha Institute of Nursing Sciences, \\ Nitte University, Paneer, M angalore - 575 018, India. \\ Correspondence : \\ Sujatha $\mathbf{R}$. \\ Professor \& HOD, Nitte Usha Institute of Nursing Sciences, Department of Pediatric Nursing, \\ Nitte University, M angalore- 575018, India \\ Mobile : +91 9880901687 E-mail : sujathakannappan@ gmail.com
}

\begin{abstract}
:
Background : Overweight has become one of the common health concerns. A few studies have noted a possible association between iron-d eficiency anemia and overw eight. As many as 3crore Indians are overw eight, and obesity continues rise, says statistics revealed by the National Family Health Survey (NFHS2010), Around 20\% of school-going children are overweight.

M aterials and M ethods: In this study survey research approach and comparative descriptive design was adopted. The sample size was 300 adolescents. 300 adolescents were selected by convenient sampling technique, out of which 225 were normal weight adolescents and remaining. Among 225 normal weight adolescents 50 adolescents were selected by simple random sampling technique (lottery method) and out of 75 overweight adolescents, 50 overweight adolescents were selected by convenient sampling technique. Initially BMI identified, Talliquis method was used for identifying the anemia. Peripheral smear test used for identifying the iron deficiency anaemia.

Results : The data were analyzed by using descriptive and inferential statistics. The result shows that out of 300 adolescents 75 ( $25 \%$ ) of adolescents were overweight. Out of 100 children (50+50) 19(38\%) were anemic in adolescents with overweight and seven (14\%) were anemic in adolescents with normal weight. Out of the total 26 adolescents with anemia (19-overweight and 7- normal weight) no occurrence of iron deficiency anemia was found. There is no significant difference in occurrence of anemia between overweight and normal weight adolescence.

Interpretation and conclusion : The find ings of the study indicates that majority of the overweight adolescents were anemic compare to normal-weight adolescents. There is no association between the occurrence of anemia and demographic variables like age, food habits, physical activity, menstrual problemsetc.
\end{abstract}

Keywords: Adolescents, anemia, overweight, normal weight, Iron deficiency anemia.

\section{Introduction:}

Overweight has become one of the common health concerns. A few studies have noted a possible association between iron-deficiency anemia and overweight. The prevalence of overweight has been increased because of

\section{Access this article online Quick Response Code}

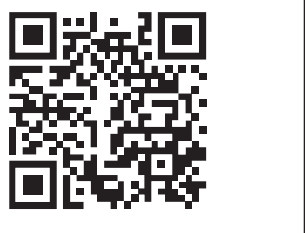

the lifestyle and socioeconomic status, a d vancement in entertainment and technology such as television, computer, and videogames. The National health and Nutrition examination survey reported that the prevalence of overweight children doubled and prevalence overweight adolescents tripled between 1980 and 2000.

As many as 3 crore Indians are overweight, and obesity continues rise, says statistics revealed by the National Family Health Survey (NFHS-2010), Around 20\% of schoolgoing children are overweight. And in Bangalore obesity is reaching epidemic proportions, with around $25 \%$ of city children between the age group of four to 12 , suffering from obesity ${ }^{1}$.

The prevalence of obesity has increased at an epidemic rate, and obesity has become one of the most common 
health concerns in the United States. A few small studies have noted a possible association between iron deficiency and obesity.

Obesity is associated with low-serum iron concentrations. The inverse relationship between iron status and adiposity was first reported in 1962, when Wenzel et al, unexpectedly found a significantly lower mean serum iron concentration in obese compared with non-obese adolescents ${ }^{2-3}$.

The incidence of overweight in adolescence rapidly rising throughout the world, and also they are prone to get iron deficiency anemia. In an article published in health news on October 5, 2004, reveals that adolescents with higher body massindexare prone for iron deficiency anemia ${ }^{4}$.

The incidence of overweight has increased at epidemic rate, over weight among adolescents has become one of the most common health concerns. The general public often perceives that overweight individuals are healthy, well-nourished and free from illness. A few studies have noted a possible association between iron deficiency anemia and overweight.

The prevalence of overweight has been increased because of the lifestyle, socioeconomic status, advancement in entertainment and technology such as television, computer, and video games. Now a days overweight is more common among adolescents. National health and Nutrition examination survey reported that the prevalence of overweight children doubled and prevalence overweight adolescents tripled between 1980 and $2000^{5}$.

The etiology of the hypoferremia of obesity is uncertain. Among the proposed causes are deficient iron intake from an iron poor diet, and deficient iron stores owing to greater iron requirements in obese adults because of their larger blood volume ${ }^{6}$.

\section{Objectives of the Study:}

- To estimate the occurrence of overweight among adolescents.

- To estimate the occurrence of anemia among overweight and normal weight adolescents.

- To estimate the occurrence of iron deficiency anemia among overweight and normal weight adolescents.

- To compare the occurrence of anemia between overweight and normal-weight adolescents.

- To find out the association between the occurrence of anemia and selected demographic variables.

- To find out the association between the occurrence of iron deficiency anemia and selected demographic variables.

\section{Materials and methods}

\section{A) Study Design}

Research Approach:

In this study survey research approach was adopted.

Research Design:

The research design adopted for the study was comparative descriptive design.

\section{b) Subjects}

The sample size was 300 adolescents.

\section{c) Specific Methods}

300 adolescents were selected by convenient sampling technique, out of which 225 were normal weight adolescents and remaining. Among 225 normal weight adolescents 50 adolescents were selected by simple random sampling technique (lottery method) and out of 75 overweight adolescents, 50 overweight adolescents were selected by convenient sampling technique.

\section{d) Procedures}

For identifying the BMI the following assessments were done.

\section{v Measuringthe height:}

Adolescents were asked to remove their shoes and they were made to stand with their back to the height rule (against the wall). Standing in the Frankfurt, by using the inch tape measure the height.

\section{$v$ Measuringthe weight:}

Zero error corrected on the weighing scale. Adolescents were allowed to stand in the weighing machine without 
shoe or any objects in hands. Then weight was measured and recorded.

\section{$\checkmark$ Determination of Body M ass Index:}

BMI is identified by using the following formula,

BMI = weight $(\mathrm{kg}) /$ height $\left(\mathrm{m}^{2}\right)$

For identifying the anaemia the following assessment wasdone.

v Hemoglobin estimation: (Talliquis method)

By using a spirit swab, fingertip was cleansed and allowed the spirit to dry. By using a lancet, a prick in the fingertip was made and a drop of blood was allowed into the Talliquis paper. Keep it for drying, check the color of the filter paper. From the Talliquis booklet it was compared and hemoglobin level was estimated.

For identifying the iron deficiency anaemia the following assessment wasdone.

\section{v Peripheral smeartest:}

Adolescents who have $\mathrm{Hb}$ less than $10 \mathrm{mg} / \mathrm{dl}$ were selected for peripheral smear test. Blood was collected in EDTA vaccutainer and sent to hematology lab for the peripheral smear checking to rule out the iron deficiency ${ }^{10}$.

Results:

\section{Section I}

Description of demographic characteristics

Majority, 70 (70\%) of the adolescents was girls and 30 (30\%) were boys. M ost of the adolescents 42 (42\%) study in the $11^{\text {th }}$ standard. 74 (74\%) of adolescents were consuming mixed diet. 50 (50\%) of adolescents were coming to school by private bus. 51 (51\%) of students spending the leisure time by watching television. 58 (83\%) of adolescence were not taken iron supplementation and 69 (69\%) didn't take de-worming tablets.

\section{Section II}

\section{Estimation Of Over Weight Among Adolescents Percentage of Overweight Adolescents}

Out of 300 adolescents75 $(25 \%)$ of adolescents were overweight.
Identification Of Anemia AmongAdolescents Number of Anemic Cases Detected Among Overweight and Normal Weight Adolescents

19(38\%) were anemic in adolescents with overweight and seven (14\%) were anemic in adolescents with normal weight.

\section{Identification of I D A Among Adolescents}

Number of iron deficiency Anemia Cases Detected among Overweight and Normal weight Adolescents

26 anemic adolescents were found among Overweight and Normal weight Adolescents were not having iron deficiency anemia found after the peripheral smear investigation.

There were no iron-deficiency anemia found in the selected samples.

Comparison of the Occurrence of Anemia Between Overweight and Normal Weight Adolescents

Occurrence of Anemia between Overweight and Normal

\section{Weight Adolescents}

Since $t$ calculated value 1.432is less than of table value $\{2.064\}$ at 0.05 level of significance $\{p>0.05\}$, research hypothesis is rejected. There is no significant difference in occurrence of anemia between overweight and normal weight adolescence.

\section{Section III}

Association between Occurrence of Anemia and Selected Demographic Variables

The calculated chi- square values, which is less than the table values $(p>0.05)$ at $5 \%$ level of significance.

Hence the research hypothesis $\mathrm{H} 4$ is rejected indicating that there is no significant association between occurrence of anemia and selected demographic variables, like age (1.790\%), gender (0.356), education (2.552), income of the family(0.431), food habit (3.163), family history of overweight (0.253), mode of transportation (1.210), spending the leisure time (3.240).

\section{Discussion :}

The findings of the study indicates that majority of the overweight adolescents were anemic compare to normalweight adolescents. 


\begin{tabular}{|c|c|c|}
\hline \multirow{2}{*}{\multicolumn{3}{|c|}{$\begin{array}{l}\text { DEM OGRAPHIC VARIABLES } \\
1 \text { 1.AGE }\end{array}$}} \\
\hline & & \\
\hline 15years & 19 & $19 \%$ \\
\hline 16years & 38 & $38 \%$ \\
\hline 17years & 43 & $43 \%$ \\
\hline \multicolumn{3}{|l|}{ 2.GENDER } \\
\hline Male & 30 & $30 \%$ \\
\hline Female & 70 & $70 \%$ \\
\hline \multicolumn{3}{|l|}{ 3. EDUCATION } \\
\hline $10^{\text {th }} \mathrm{std}$ & 22 & $22 \%$ \\
\hline $11^{\text {th }}$ std & 42 & $42 \%$ \\
\hline $12^{\text {th }}$ std & 36 & $36 \%$ \\
\hline \multicolumn{3}{|c|}{ 4. EDUCATIONALSTATUSOFM OTHER } \\
\hline No formal education & & \\
\hline High School & 3 & $3 \%$ \\
\hline Graduates & 56 & $56 \%$ \\
\hline \multicolumn{3}{|c|}{ 5. EDUCATIONALSTATUSOFFATHER } \\
\hline No Formal Education & 4 & $4 \%$ \\
\hline High School & 39 & $39 \%$ \\
\hline Graduate & 57 & $57 \%$ \\
\hline \multicolumn{3}{|l|}{ 6. INCOME OF THE FAMILY } \\
\hline $\mathrm{Rs}<3000$ & 0 & $0 \%$ \\
\hline Rs3001-5001 & 8 & $8 \%$ \\
\hline Rs5001-7000 & 55 & $55 \%$ \\
\hline Rs $>7001$ & 37 & $37 \%$ \\
\hline \multicolumn{3}{|l|}{ 7. FOOD HABIT } \\
\hline Vegetarian & 4 & $4 \%$ \\
\hline Non-Vegetarian & 22 & $22 \%$ \\
\hline Mixed & 74 & $74 \%$ \\
\hline \multicolumn{3}{|l|}{ 8.HISTORY OFILLNESS } \\
\hline Yes & 35 & $35 \%$ \\
\hline No & 65 & $65 \%$ \\
\hline \multicolumn{3}{|c|}{ 9.FAMILY HISTORYOFOVERWEIGHT } \\
\hline Yes & 27 & $27 \%$ \\
\hline No & 73 & $73 \%$ \\
\hline \multicolumn{3}{|c|}{ 10. MODE OF TRANSPORTATION TO SCHOOL } \\
\hline By Walking & 7 & $7 \%$ \\
\hline Cycling & 15 & $15 \%$ \\
\hline Private Bus & 50 & $50 \%$ \\
\hline School Vehicle & 28 & $28 \%$ \\
\hline \multicolumn{3}{|c|}{ 11. SPENDING THE LEISURETIME } \\
\hline Play & 33 & $33 \%$ \\
\hline Exercise & 2 & $2 \%$ \\
\hline Watching Television & 51 & $51 \%$ \\
\hline ReadingBooks & 14 & $14 \%$ \\
\hline \multicolumn{3}{|c|}{ 12. IN TAKE OF DE-WORM ING TABLETS } \\
\hline Yes & 31 & $31 \%$ \\
\hline No & 69 & $69 \%$ \\
\hline $\begin{array}{ll}\text { ONLY FOR GIRLS } & n=70\end{array}$ & & \\
\hline \multicolumn{3}{|l|}{ 13. AGE OFMENARCHE } \\
\hline 13years & 6 & $9 \%$ \\
\hline 14years & 49 & $70 \%$ \\
\hline >14years & 15 & $21 \%$ \\
\hline
\end{tabular}

\begin{tabular}{|c|c|c|}
\hline DEM OGRAPHIC VARIABLES & FREQUENCY & PERCENTAGE (\%) \\
\hline \multicolumn{3}{|c|}{ 14.REGULARITY OF MENSTRUATION } \\
\hline Regular & 57 & $81 \%$ \\
\hline Irregular & 13 & $19 \%$ \\
\hline \multicolumn{3}{|c|}{ 15.PROBLEMSDURING MENSTRUATION } \\
\hline Yes & 6 & $9 \%$ \\
\hline No & 64 & $91 \%$ \\
\hline \multicolumn{3}{|c|}{ 16. INTAKE OF IRON SUPPLEM ENTATION } \\
\hline Yes & 12 & $17 \%$ \\
\hline No & 58 & $83 \%$ \\
\hline
\end{tabular}

ESTIM ATION OF OVER WEIGHT AMONG ADOLESCENTS

Percentage of Overweight Adolescents

$n=300$

\begin{tabular}{|c|c|c|}
\hline No. of adolescents & No. of overweight & Percentage \\
\hline & adolescents & \\
\hline 300 & 75 & $25.00 \%$ \\
\hline
\end{tabular}

\section{IDENTIFICATION OF ANEM IA AMONG ADOLESCENTS}

Number of Anemic Cases Detected Among Overweight And Normal Weight Adolescents

\begin{tabular}{|c|c|c|c|}
\hline \multicolumn{2}{|c|}{$\begin{array}{c}\text { Overweight adolescents } \\
\mathrm{n}=50\end{array}$} & $\begin{array}{c}\text { Normal weight adolescents } \\
\mathrm{n}=50\end{array}$ \\
\hline No & Percentage & No & Percentage \\
\hline 19 & $38 \%$ & 7 & $14 \%$ \\
\hline
\end{tabular}

\section{IDENTIFICATION OFID A AM ONG ADOLESCENTS}

Number of iron deficiency Anemia Cases Detected Among Overweight and Normal weight Adolescents

\begin{tabular}{|l|c|c|c|}
\hline ADOLESCENTS & \multicolumn{2}{|c|}{ ANEMICCASES } & IRON DEFICIENCY \\
\cline { 2 - 3 } & NO. & $\%$ & ANEM IA \\
\hline Overweight $\mathrm{n}=50$ & 19 & $38 \%$ & Nil \\
\hline Normal weight $\mathrm{n}=50$ & 7 & $14 \%$ & Nil \\
\hline
\end{tabular}

\section{COMPARISON OF THE OCCURRENCE OF ANEMIA BETWEEN OVERWEIGHT AND NORMAL WEIGHT ADOLESCENTS}

Occurrence Of Anemia Between Overweight And Normal Weight Adolescents

\begin{tabular}{|l|c|c|c|c|c|c|}
\hline GROUP & N & M EAN & 't' value & SD & df & LOS \\
\hline $\begin{array}{l}\text { Normal weight } \\
\text { adolescents }\end{array}$ & 7 & 10.6286 & 1.432 & .74992 & 24 & .165 \\
\hline $\begin{array}{l}\text { Over weight } \\
\text { adolescents }\end{array}$ & 19 & 9.7105 & & 1.61689 & & $p>0.05$ \\
\hline
\end{tabular}

\section{Estimation of overweight amongadolescents}

From the 300 samples 75 (25\%) adolescents were identified to be overweight. 
Identification of anemia among adolescents:-

Out of the 50 adolescents with overweight 19(38\%) were anemic and in 50 normal-weight adolescents 7(14\%) were anemic. A supportive study was conducted among 317 adolescents (10- 19 years) Government school girls in Bhopal city. The adolescents were divided into three groups by random sampling method. Level of anemia was higher in early adolescents (10 - 13 years) age group (81\%) as compared to the middle (58.3\%) and late adolescents (17 - 19 years) age group girls (48.7\%).

\section{Identification of iron-deficiency anemia among adolescents.}

There was no iron-deficiency anemia found in the 19 (38\%) adolescents with overweight and seven (14\%) adolescents with normal weight with anemia. So $\mathrm{H} 1$ hypothesis is rejected. So there is no significant difference in the occurrence of iron deficiency between overweight and normal weight.

A supportive study was conducted in Israel to identify the prevalence of iron deficiency anemia in overweight, obese and normal weight children. Data was collected from 321 adolescents. The study revealed that iron deficiency anemia was noted among $38.8 \%$ of the obese adolescents, $12.1 \%$ overweight adolescents and $4.4 \%$ of the normal weight ado lescents ${ }^{7}$

Another study conducted USA to identify Overweight children and adolescents: a risk group for iron deficiency, among 9698 adolescents.

The study revealed that out of 9698 children, $13.7 \%$ were at risk for overweight and $10.2 \%$ were overweight. Iron deficiency was most prevalent among 12- to 16-year-old subjects $(4.7 \%)$, followed by 2 - to 5 -year-old subjects $(2.3 \%)$ and then 6 - to 11-year-old subjects $(1.8 \%)$. Overweight 2- to 5-year-old subjects $(6.2 \%)$ and overweight 12 - to 16-year-old subjects (9.1\%) demonstrated the highest prevalence of iron deficiency. Overall, the prevalence of iron deficiency increased as BMI increased from normal weight to at risk for overweight to overweight ( $2.1 \%, 5.3 \%$, and $5.5 \%$, respectively), and iron deficiency was particularly common among adolescents $(3.5 \%, 7.2 \% \text {, and } 9.1 \% \text {, respectively })^{8}$.

A similar study indicated that the prevalence of anemia was $52.88 \%$ in the school children of Kattankulathur. The results of the study showed that $52.88 \%$ were anemic, the prevalence of anemia in girls (67.77\%) was higher than in the boys (35.55\%).The prevalence of anemia was very much higher in girls when compared to boys during between the age of 8 and 14 years. The anemia was graded according to WHO standards. It showed that $30.4 \%$ of girls were mildly anemic, $37.33 \%$ were moderately anemic and there were no severely anemic children diagnosed ${ }^{9}$.

It was observed that $77.7 \%$ of tribal children of Mysore District, Karnataka were suffering from anemia and also indicates similar results that the prevalence of anemia was significantly higher in girls when compared to boys (girls $83.33 \%$ and boys $70.89 \%)^{10}$.

The overall prevalence of anemia among school-going adolescent girls of urban Kathmandu, Nepal was $54.4 \%{ }^{11}$.

Another study of 393 children reported the prevalence of $66.4 \%$ anemia amongst primary school children (6-11 years) in the national capital territory of Delhi12.

\section{Comparison of the occurrence of anemia between overweight and normal-weight adolescents.}

According to independent ' $t$ ' test there is no significant difference in occurrence of anemia between overweight and normal-weight adolescents. So $\mathrm{H} 2$ hypothesis is rejected.

\section{Association between the occurrence of anemia and selected demographic variables}

There is no association between the occurrence of anemia and demographic variables like age, food habits, physical activity, menstrual problems etc. So $\mathrm{H} 4$ hypothesis is rejected.

\section{Conclusion:}

The findings of the study indicates that majority of the overweight adolescents were anemic compare to normal- 
weight adolescents. In our society majority of the parents believe that their young child's excess fat is normal, that it will disappear as the child grows, and that it isn't a real health concern. This is not the case for most overweight children, who are very likely to become overweight adults. Anemia is high among children heavier and more overweight. Further examination into the causes of anemia and overweight is warranted.

\section{Reference:}

1. www.indushealthplus.com/karnataka-health-statistics/-41k

2. Wenzel BJ, Stults HB, Mayer J: Hypoferraemia in obese adolescents.Lancet 1962, 2:327-28. PubM edAbstract

3. Seltzer CC, Mayer J: Serum iron and iron-binding capacity in adolescents: Comparison of obese and non-obese subjects.Am J Clin Nutr 1963, 13:354-61 PubM edAbstract

4. Beryl M ohanraj, Chellarani Vijayakumar; Indian Journal of Paediatrics, Volumell: Issue 1; 2004 Page:47-49.

5. Wong's, Essential of paediatric nursing, $8^{\text {th }}$ edition, Elsevier publication, M issuri.

6. Seltzer CC, Mayer J: Serum iron and iron-binding capacity in adolescents: Comparison of obese and non-obese subjects. Am J Clin Nutr 1963, 13:354-361 PubM edAbstract

7. Nead. G. Karen, Hailerman. S. Jill; J ournal of the American Academy of Pediatrics; Indian edition; volume 16,no: 1-6, Jan- Dec 2004

8. Nead KG, Halterman JS, Kaczorowski JM, Auinger P, Weitzman M. Overweight children and adolescents: a risk group for iron deficiency. Pediatrics. 2004Jul;114(1):104-8. PubM ed - indexed for M EDLINE

9. B Sudhagandhi, Sivapatham Sundaresan, W Ebenezer William, A Prema Prevalence of anemia in the school children of Kattankulathur, Tamil Nadu, India, SRM M edical College Hospital and Research Centre, SRM University, Tamil Nadu, India.

10. Jai Prabhakar SC, Gangadhar M R. Prevalence of anemia in Jenukuruba Primitive Tribal Children of M ysore District, Karnataka. Anthropologist 2009;11:49-51.

11. Tiwari K. Seshadri S. The prevalence of anemia and morbidity profile among school going adolescent girls of urban Kathmandu, Nepal. J Nep Med Assoc 2000;39:319-25

12. Sethi V, Goindi G, Kapil U. The Prevalence of anemia amongst primary school age children (6-11 years) in national capital territory of Delhi. Indian J Pediatr 2003;70:519-20. PUBM ED

\section{Acknowledgement :}

Our sincere thanks to Nitte University for funding this research project and supporting us in every step during the process. We also thank M rs. Vandhana, Statistician, NUINS, M angalore, for the guidance provided related to analysis of the study. 